\title{
The risk of COVID-19 in survivors of domestic violence and abuse
}

\author{
Joht Singh Chandan ${ }^{1 * \dagger} \mathbb{B}$, Anuradhaa Subramanian ${ }^{1 \dagger}$, Jaidev Kaur Chandan², Krishna M. Gokhale ${ }^{1}$, Alecs Vitoc ${ }^{1}$, \\ Julie Taylor ${ }^{3,4}$, Caroline Bradbury-Jones ${ }^{3}$, Siddhartha Bandyopadhyay ${ }^{5}$ and Krishnarajah Nirantharakumar ${ }^{1}$
}

\begin{abstract}
A 'shadow pandemic' of domestic violence and abuse (DVA) has emerged secondary to strict public health measures containing the spread of SARS-CoV-2. Many countries have implemented policies to allow the free movement of DVA survivors in attempts to minimise their exposure to abusive environments. Although these policies are well received, as a result there is a possibility of increased COVID-19 transmission within this vulnerable group who are not currently prioritised for vaccination. Therefore, we aimed to compare the risk of developing suspected or confirmed COVID-19 in women (aged over 16 years) exposed to DVA against age-sex-matched unexposed controls, following adjustment for known COVID-19 risk factors. A population-based retrospective open cohort study was undertaken between the 31 January 2020 and 28 February 2021 using The Health Improvement Network' database. We identified 10,462 eligible women exposed to DVA who were matched to 41,467 similarly aged unexposed women. Following adjustment for key covariates, women exposed to DVA were at an increased risk (aHR 1.57; 95\% Cl 1.29-1.90) of suspected/confirmed COVID-19 compared to unexposed women. These findings support previous calls for positive policy action improving DVA surveillance and prioritising survivors for COVID-19 vaccination.
\end{abstract}

Keywords: Domestic abuse, Domestic violence, Epidemiology, COVID-19

\section{Background}

A 'shadow pandemic' of domestic violence and abuse (DVA) has emerged secondary to strict public health measures containing the spread of SARS-CoV-2 [1]. Some of the risk factors mediating this relationship include movement restrictions, loss of income, isolation, overcrowding and high levels of stress and anxiety, all of which put victims of domestic abuse at a disproportionally increased risk of harm $[2,3]$. The relationship between containment measures and increased rates of violence against women have occurred in other recent epidemics such as the Ebola

\footnotetext{
* Correspondence: Joht.chandan@nhs.net

${ }^{\dagger}$ Joht Singh Chandan and Anuradhaa Subramanian are joint first authors. ${ }^{1}$ Institute of Applied Health Research, College of Medical and Dental Sciences, University of Birmingham, Birmingham B152TT, UK

Full list of author information is available at the end of the article
}

outbreak in West Africa, Cholera outbreaks in Haiti and Yemen as well as the Zika outbreak $[1,4,5]$. Consequently, many countries have implemented policies to allow the free movement of DVA survivors in attempts to minimise their exposure to abusive environments and to facilitate access to support [6]. However, the encouraged freedom of travel (compounded by increased prevalence of comorbidities in DVA survivors) can potentially increase risk of COVID-19 exposure (and potential transmission) for this vulnerable cohort [7, 8]. To further exacerbate this risk, perpetrators may control or coerce survivors by (1) acting as a barrier preventing access to healthcare services or treatment or (2) threatening or enacting purposeful exposure to COVID-19 within the household $[9,10]$.

(c) The Author(s). 2021 Open Access This article is licensed under a Creative Commons Attribution 4.0 International License, which permits use, sharing, adaptation, distribution and reproduction in any medium or format, as long as you give appropriate credit to the original author(s) and the source, provide a link to the Creative Commons licence, and indicate if changes were made. The images or other third party material in this article are included in the article's Creative Commons licence, unless indicated otherwise in a credit line to the material. If material is not included in the article's Creative Commons licence and your intended use is not permitted by statutory regulation or exceeds the permitted use, you will need to obtain permission directly from the copyright holder. To view a copy of this licence, visit http://creativecommons.org/licenses/by/4.0/ The Creative Commons Public Domain Dedication waiver (http://creativecommons.org/publicdomain/zero/1.0/) applies to the data made available in this article, unless otherwise stated in a credit line to the data. 


\section{Methods}

We conducted a population-based retrospective open cohort study between the 31 January 2020 and 28 February 2021 using 'The Health Improvement Network' (THIN) database.

THIN database, hosted by Cegedim Health Data, consists of a sample of UK electronic medical records taken from 867 general practices (covering approximately 6\% of the population) which have commissioned the use of the Vision software system [11, 12]. General practitioners (GPs), within the UK, have the option to subscribe to any of the NHS registered system suppliers and only those who have selected the Vision system will contribute data to THIN research database [13].

Following inception, THIN has been shown to be representative of the UK population in terms of demographic structure and prevalence of key comorbidities [14]. Symptoms, examinations, and diagnoses in THIN are recorded using a hierarchical clinical coding system called Read codes [15]. Of note, the database has been used extensively to examine outcomes of women exposed to DVA [7, 16-19]. General practices were included 1 year following their (1) instalment of electronic practice records and (2) acceptable mortality recording date to meet quality standards [20]. During the study period, 344 general practices $(7,026,841$ patients) met this inclusion criteria. Of those eligible general practices, only patients aged over 16 years, coded as female and registered with their general practice for at least 12 months prior to study start date (to ensure adequate time for baseline data recording to take place), were included. This led to a total of 2,512,769 remaining eligible patients for inclusion in the study.

Women (aged 16+ years) in the exposed group were defined as those with clinically coded exposure to DVA (Additional file 1: Table S1) who were then age- and sex-matched to those without such a recorded code (unexposed group). The Read code selection process has been previously described in the literature [21]. Ascertainment of exposure to DVA included the presence of broad codes such as '14X8.00: Victim of domestic violence' as well as more specific exposures to sub-types of DVA such as '14XD200: H/O domestic sexual abuse'.

The index date in the exposed group was the date of the first code relating to DVA exposure or when they became eligible to enter the study. To mitigate immortality time bias, the same index date was assigned to the corresponding unexposed patient. The follow-up period for each patient was from the index date until the exit date, defined as the earliest of either of the following: study end date, last date of data collection from a given general practice, date patient transferred from general practice, date of death or date the outcome of interest occurred. The outcome of interest was the presence of a GP recorded diagnosis of suspected or confirmed COVID-19. Covariates (sociodemographic, lifestyle risk factors and comorbidities) relating to known risk factors for the development of COVID-19 complications were also recorded at each patient's study entry [8].

Crude incidence rates per 1000 person-years were estimated for the exposed and the unexposed groups. A Cox proportional hazards regression model was then undertaken to determine crude and adjusted hazard ratios (HR) with 95\% confidence intervals (CI) describing the COVID-19 risk in the exposed compared to the unexposed group. Where there were missing data in our covariates, they were treated as a separate missing category and included in the final analysis.

To examine the impact of recent DVA exposure and risk of outcome development, we have also undertaken a sensitivity analysis including only those with a code for DVA exposure in the 1 year prior to the study start date or during the study period.

\section{Findings}

We identified 10,462 eligible women exposed to DVA who were matched to 41,467 similarly aged unexposed women. At study entry, in keeping with known literature [7], the exposed group had increased rates of smoking and a greater prevalence of comorbidities compared to the unexposed group (Table 1).

During the study period, there were 190 (1.8\%) new diagnoses of suspected/confirmed COVID-19 in the exposed cohort relating to an IR of 20.2 per 1000 person years compared to 8.6 per 1000 person years (324 $(0.8 \%)$ in the unexposed cohort (Table 2). This translated to an unadjusted HR of 2.36 (95\% CI 1.98-2.83). Following adjustment for key covariates (these include (1) sociodemographic characteristics-age and ethnicity; (2) lifestyle and metabolic profile measures-smoking status, body mass index (BMI), systolic and diastolic blood pressure and estimated glomerular filtration rate (eGFR); (3) comorbidity-type 2 diabetes mellitus, cardiovascular disease (peripheral vascular disease, stroke, ischaemic heart disease, atrial fibrillation and heart failure), severe respiratory disease, asthma, chronic obstructive pulmonary disease, cancer, liver disease (mild, moderate and severe), rheumatic disease (rheumatoid arthritis, lupus and psoriasis) and neurological disorders (Parkinson's disease, motor neuron disease, multiple sclerosis, myasthenia gravis and epilepsy), dementia, solid organ transplants, and use of immunosuppressive drug therapies), the risk remained statistically significant (aHR 1.57; 95\% CI 1.29-1.90). When examining suspected (aHR 1.61; 95\% CI 1.27-2.03) and confirmed (aHR 1.56; 95\% CI 1.132.16) COVID-19 outcomes separately, the findings remained similar. 
Table 1 Baseline characteristics

\begin{tabular}{|c|c|c|}
\hline Total number & $\begin{array}{l}\text { Exposed group } \\
(n=10,462)\end{array}$ & $\begin{array}{l}\text { Unexposed group } \\
(n=41,467)\end{array}$ \\
\hline Age [mean (SD)] & $42.38(13.49)$ & $41.74(13.42)$ \\
\hline Age [median (IQR)] & $41.00(32.00-51.00)$ & $40.00(32.00-50.00)$ \\
\hline \multicolumn{3}{|l|}{ Age categories [n (\%)] } \\
\hline $16-30$ years & $1797(17.18)$ & $7831(18.88)$ \\
\hline $30-40$ years & $3087(29.51)$ & $12241(29.52)$ \\
\hline $40-50$ years & $2561(24.48)$ & $10131(24.43)$ \\
\hline $50-60$ years & $1914(18.29)$ & $7307(17.62)$ \\
\hline $60-70$ years & $726(6.94)$ & $2610(6.29)$ \\
\hline$>70$ years & $377(3.60)$ & $1347(3.25)$ \\
\hline BMI [mean (SD)] & $27.09(6.78)$ & $26.47(6.60)$ \\
\hline BMI [median (IQR)] & $25.00(22.00-30.00)$ & $24.00(21.00-29.00)$ \\
\hline \multicolumn{3}{|l|}{ BMI categories [n (\%)] } \\
\hline Underweight $(<18.5)$ & $433(4.14)$ & $1200(2.89)$ \\
\hline Normal weight (18.5-24.9) & $3493(33.39)$ & 13913 (33.55) \\
\hline Overweight (25-30) & $2383(22.78)$ & $7362(17.75)$ \\
\hline Obese $(>30)$ & $2412(23.05)$ & $6970(16.81)$ \\
\hline Missing & $1741(16.64)$ & 12022 (28.99) \\
\hline \multicolumn{3}{|l|}{ Smoker categories [n (\%)] } \\
\hline Non-smoker & $3690(35.27)$ & 19809 (47.77) \\
\hline Ex-smoker & $1807(17.27)$ & $5331(12.86)$ \\
\hline Smoker & $4317(41.26)$ & $7989(19.27)$ \\
\hline Missing & $648(6.19)$ & $8338(20.11)$ \\
\hline \multicolumn{3}{|l|}{ Ethnicity $[n(\%)]$} \\
\hline Caucasian & $5780(55.25)$ & $13184(31.79)$ \\
\hline South Asian & $456(4.36)$ & $785(1.89)$ \\
\hline Black Afro-Caribbean & $303(2.90)$ & $510(1.23)$ \\
\hline Mixed race & $117(1.12)$ & $225(0.54)$ \\
\hline Chinese/Middle Eastern/others & $1848(17.66)$ & $6816(16.44)$ \\
\hline Missing & $1958(18.72)$ & $19947(48.10)$ \\
\hline eGFR [mean (SD)] & $99.98(18.39)$ & $100.04(18.72)$ \\
\hline eGFR [median (IQR)] & $101.00(88.00-112.00)$ & $101.00(87.00-113.00)$ \\
\hline \multicolumn{3}{|l|}{ eGFR categories $[n(\%)]$} \\
\hline Stage $1 / 2(>60 \mathrm{~mL} / \mathrm{min})$ & $7020(67.10)$ & $17329(41.79)$ \\
\hline Stage $3(30-59 \mathrm{~mL} / \mathrm{min})$ & $135(1.29)$ & $293(0.71)$ \\
\hline Stage $4(<30 \mathrm{~mL} / \mathrm{min})$ & $8(0.08)$ & $33(0.08)$ \\
\hline Missing & $3299(31.53)$ & $23812(57.42)$ \\
\hline Systolic BP [mean (SD)] & $120.42(15.23)$ & $119.67(14.55)$ \\
\hline Systolic BP [median (IQR)] & $120.00(110.00-130.00)$ & $120.00(110.00-130.00)$ \\
\hline \multicolumn{3}{|l|}{ Systolic BP categories [n (\%)] } \\
\hline Normal (<120 mm Hg) & $4463(42.66)$ & $15294(36.88)$ \\
\hline Prehypertension (120-129 mm Hg) & $2357(22.53)$ & $8803(21.23)$ \\
\hline Hypertension stage $1(130-139 \mathrm{~mm} \mathrm{Hg})$ & $1529(14.61)$ & $5159(12.44)$ \\
\hline Hypertension stage $2(140-149 \mathrm{~mm} \mathrm{Hg})$ & 1066 (10.19) & $3003(7.24)$ \\
\hline
\end{tabular}


Table 1 Baseline characteristics (Continued)

\begin{tabular}{|c|c|c|}
\hline Total number & $\begin{array}{l}\text { Exposed group } \\
(n=10,462)\end{array}$ & $\begin{array}{l}\text { Unexposed group } \\
(n=41,467)\end{array}$ \\
\hline Missing & $1047(10.01)$ & $9208(22.21)$ \\
\hline \multicolumn{3}{|l|}{ Other co-morbidities [n (\%)] } \\
\hline Hypertension & $2289(21.88)$ & $6591(15.89)$ \\
\hline Diabetes & $449(4.29)$ & $881(2.12)$ \\
\hline Cancer & $225(2.15)$ & $614(1.48)$ \\
\hline Cardiac diseases & $373(3.57)$ & $627(1.51)$ \\
\hline Myocardial infarction & $71(0.68)$ & $109(0.26)$ \\
\hline Heart failure & $43(0.41)$ & $96(0.23)$ \\
\hline Stroke/TIA & $205(1.96)$ & $274(0.66)$ \\
\hline Atrial fibrillation & $40(0.38)$ & $79(0.19)$ \\
\hline Peripheral vascular disease & $83(0.79)$ & $147(0.35)$ \\
\hline Chronic liver disease & $190(1.82)$ & $167(0.40)$ \\
\hline Mild liver disease & $185(1.77)$ & $163(0.39)$ \\
\hline Moderate/severe liver disease & $22(0.21)$ & $14(0.03)$ \\
\hline Neuron disease & $330(3.15)$ & $674(1.63)$ \\
\hline Parkinson's disease & $10(0.10)$ & $9(0.02)$ \\
\hline Motor neuron disease & $1(0.01)$ & $1(0.00)$ \\
\hline Multiple sclerosis & $35(0.33)$ & $92(0.22)$ \\
\hline Epilepsy & $286(2.73)$ & $572(1.38)$ \\
\hline Myasthenia gravis & $2(0.02)$ & $5(0.01)$ \\
\hline Rheumatic diseases & $589(5.63)$ & $1455(3.51)$ \\
\hline SLE & $30(0.29)$ & $38(0.09)$ \\
\hline Rheumatoid arthritis & $82(0.78)$ & $150(0.36)$ \\
\hline Psoriasis & $489(4.67)$ & $1283(3.09)$ \\
\hline Dementia & $45(0.43)$ & $64(0.15)$ \\
\hline Severe respiratory disease & $69(0.66)$ & $99(0.24)$ \\
\hline Asthma & $2296(21.95)$ & $5781(13.94)$ \\
\hline COPD & $310(2.96)$ & $296(0.71)$ \\
\hline Solid organ transplant & $7(0.07)$ & $23(0.06)$ \\
\hline \multicolumn{3}{|c|}{ Prescriptions (any time prior to index date) $[n(\%)]$} \\
\hline Immunosuppressive drug therapies & $25(0.24)$ & $70(0.17)$ \\
\hline
\end{tabular}

There were 1151 women exposed to DVA in the 1 year prior to the study start date or during the study period eligible in the sensitivity analysis who were matched to 4561 women. The results were largely similar to the main cohort whereby the exposed group had a further increased risk of a new diagnosis of suspected/ confirmed COVID-19 following adjustment for key covariates (aHR 2.53; 95\% CI 1.51-4.26), although it should be noted the confirmed case only subgroup analysis did not reach statistical significance. Further details can be seen in additional file 1: Table S2.

\section{Discussion}

Our findings demonstrate that despite accounting for known risk factors, individuals exposed to DVA were at an increased risk of suspected/confirmed Covid-19 as recorded in general practitioner records. It is therefore possible that a clinical-safeguarding paradox may exist whereby current policy action protecting survivors from further abuse may indeed increase their risk of COVID19. These findings support our previous calls for positive policy action improving DVA surveillance and prioritising survivors for COVID-19 vaccination $[6,22]$. 
Table 2 The risk of developing COVID-19 in the exposed group compared to the unexposed group

\begin{tabular}{|c|c|c|}
\hline \multirow[t]{2}{*}{ Total number of patients } & Exposed group & Unexposed group \\
\hline & 10,462 & 41,467 \\
\hline \multicolumn{3}{|l|}{ Suspected/confirmed COVID-19 } \\
\hline Outcome events [ $n(\%)]$ & $190(1.82)$ & $324(0.78)$ \\
\hline Person-years & 9406 & 37,901 \\
\hline Crude incidence rate/1000 person years & 20.2 & 8.55 \\
\hline Unadjusted hazard ratio $(95 \% \mathrm{Cl})$ & $2.36(1.98-2.83), p<0.001$ & \\
\hline Adjusted hazard ratio $(95 \% \mathrm{Cl})^{\mathrm{a}}$ & $1.57(1.29-1.90), p<0.001$ & \\
\hline \multicolumn{3}{|l|}{ Confirmed COVID-19 } \\
\hline Outcome events [ $n(\%)]$ & $58(0.55)$ & $135(0.33)$ \\
\hline Person-years & 9484 & 38,011 \\
\hline Crude incidence rate/1000 person years & 6.12 & 3.55 \\
\hline Unadjusted hazard ratio $(95 \% \mathrm{Cl})$ & $1.73(1.27-2.35), p<0.001$ & \\
\hline Adjusted hazard ratio $(95 \% \mathrm{Cl})^{\mathrm{a}}$ & $1.56(1.13-2.16), p=0.007$ & \\
\hline \multicolumn{3}{|l|}{ Suspected COVID-19 } \\
\hline Outcome events [n (\%)] & $138(1.32)$ & $193(0.47)$ \\
\hline Person-years & 9421 & 37,946 \\
\hline Crude incidence rate/1000 person years & 14.65 & 5.09 \\
\hline Unadjusted hazard ratio $(95 \% \mathrm{Cl})$ & $2.87(2.31-3.57), p<0.001$ & \\
\hline Adjusted hazard ratio $(95 \% \mathrm{Cl})^{\mathrm{a}}$ & $1.61(1.27-2.03), p<0.001$ & \\
\hline
\end{tabular}

${ }^{a}$ Adjusted for currently known risk factors for the development of COVID-19. These include (1) sociodemographic characteristics-age and ethnicity; (2) lifestyle and metabolic profile measures: smoking status, body mass index (BMI), systolic and diastolic blood pressure and estimated glomerular filtration rate (eGFR); (3) comorbidity - type 2 diabetes mellitus, cardiovascular disease (peripheral vascular disease, stroke, ischaemic heart disease, atrial fibrillation and heart failure), severe respiratory disease, asthma, chronic obstructive pulmonary disease, cancer, liver disease (mild, moderate and severe), rheumatic disease (rheumatoid arthritis, lupus and psoriasis), neurological disorders (Parkinson's disease, motor neuron disease, multiple sclerosis, myasthenia gravis and epilepsy), dementia, solid organ transplants and use of immunosuppressive drug therapies

Although such positive action would be recommended, we also appreciate that this cohort are traditionally a hardto-reach population often due to (1) controlling behaviours exerted by perpetrators, (2) the extent of the hidden burden of DVA not known to public sector services and (3) inadequate historical public sector responses to support this cohort leading to mistrust [23]. Additionally, practical and logistical challenges may be present for survivors further reducing their access to vaccine clinics. For example, survivors may not have access to transportation or the means to afford public travel due to ongoing financial abuse. Therefore, we recommend countries adopt the evidence-based recommendations suggested by Gavi to increase vaccination rates in hard-to-reach populations with an initial focus on reducing physical barriers to vaccine access [24]. Practically, these recommendations may include setting up pop-up clinics in the community minimising travel or where survivors have already been displaced, for example, to set up clinics within domestic violence shelters.

Despite this study having a large sample size which has been previously examined to assess health outcomes in the DVA population, the findings must be considered in light of the study limitations. Misclassification bias poses a key limitation in this study, as the prevalence of
DVA in THIN $(<0.4 \%)$ is substantially lower than the self-reported rates in the UK [25]. Although previous studies examining the health outcomes in this cohort have shown similar effect sizes to the published literature, DVA coding has yet to be validated in THIN [7, 16]. Despite the lack of validation specifically in this dataset, promisingly a recent meta-analysis demonstrated a high positive predictive value $(>85 \%)$ of intimate partner violence in other electronic health records, providing some confidence in the accuracy of recorded DVA experiences [26]. Therefore, although we may not be able to truly determine whether the misclassification bias could lead to an over or under-estimate, it appears more likely that the unexposed cohort will contain a greater proportion of miscoded events (where DVA may have occurred but was not coded) rather than the exposed cohort having miscoded events whereby DVA occurred when in fact it did not. Therefore, if the hypothesis is correct that DVA exposure may lead to increased exposure to SARS-CoV-2 then we anticipate that some of the events in the unexposed cohort may have occurred in survivors exposed to DVA, which may in turn lead to reduction of our reported effect size. A recent review exploring DVA coding in healthcare 
identified that although primary care staff appreciate the importance of recording DVA, barriers still exist relating to lack of training, unawareness of local/national guidance, confidentiality concerns and how it may affect the patient-clinician relationship [27]. As no research to date has been published suggesting a difference in DVA severity or demographic characteristics between coded and uncoded experiences of DVA, it is not yet possible to identify whether there is a systematic difference between those in the exposed group and those miscoded in the unexposed group ultimately informing us as to how this may affect the effect size reported in this study. However, it does reaffirm the importance of ensuring that our results are used to describe the effect size in those with recorded exposure to DVA.

A second key limitation relates to the inability to account for the impact of socio-economic deprivation due to this data being unavailable for the cohort during the study period. However, to mitigate this as much as possible, we have been able to match patients by the location of the general practice. Although, heterogeneity in socio-economic status is likely to remain.

In conclusion, we believe this is the first study describing the risk of COVID-19 in DVA survivors and highlights the important global public health needs of one of the most vulnerable groups in society.

\section{Abbreviations}

aHR: Adjusted hazard ratio; Cl: Confidence interval; DVA: Domestic violence and abuse; HR: Hazard ratio; IR: Incidence rate; THIN: The Health Improvement Network

\section{Supplementary Information}

The online version contains supplementary material available at https://doi. org/10.1186/s12916-021-02119-w.

Additional file 1: Table S1. Read codes used to describe exposure to domestic violence and abuse. Table S2. The risk of developing COVID-19 in the patients coded with DVA exposure in the one year prior to the study start date compared to the unexposed group

\section{Acknowledgements}

We would like to thank the team at Cegedim for their continued support in using THIN.

\section{Authors' contributions}

JSC and JKC were responsible for study conception. JSC, AS, KMG, AV and KN were responsible for data extraction and statistical analysis. JT, CB-J and SB provided subject expertise. JSC, JKC and AS were responsible for initial drafting of the manuscript. All authors (JSC, AS, JKC, KMG, AV, JT, CB-J, SB and KN) were responsible for ongoing drafts and final review of the manuscript. All authors have read and approved the final manuscript.

\section{Funding}

None

\section{Availability of data and materials}

The data and code for this study can be requested from the corresponding author and will be shared once approval is obtained from the data provider.

\section{Declarations}

Ethics approval and consent to participate

The Health Improvement Network (THIN) Database (A Cegedim Proprietary Database) data collection scheme and research carried out using THIN data were approved by the NHS South-East Multicentre Research Ethic Committee in 2003. Under the terms of the approval, studies must undergo independent scientific review. Approval for this study was obtained from the THIN Scientific Review Committee in March 2021 (SRC protocol reference 201-005). Following approval, members of the research team were authorised to access the raw data for this study. All data were anonymised prior to use. This work uses data provided by patients and collected by the NHS as part of their care and support

\section{Consent for publication}

Not applicable

\section{Competing interests}

The authors declare that they have no competing interests.

\section{Author details}

'Institute of Applied Health Research, College of Medical and Dental Sciences, University of Birmingham, Birmingham B152TT, UK. 'Warwick Medical School, University of Warwick, Coventry CV47HL, UK. ${ }^{3}$ School of Nursing, College of Medical and Dental Sciences, University of Birmingham, Birmingham B152TT, UK. “Birmingham Women's and Children's Hospitals NHS Foundation Trust, Birmingham, UK. ${ }^{5}$ The Department of Economics, University of Birmingham, Birmingham B152TT, UK.

Received: 17 May 2021 Accepted: 7 September 2021

Published online: 24 September 2021

\section{References}

1. Chandan JS, Taylor J, Bradbury-Jones C, Nirantharakumar K, Kane E, Bandyopadhyay S. COVID-19: a public health approach to manage domestic violence is needed. Lancet Public Health. 2020;5(6):e309. https://doi.org/10.1 016/S2468-2667(20)30112-2.

2. World Health Organization. Joint Leader's statement - Violence against children: a hidden crisis of the COVID-19 pandemic. 2020. https://www.who. int/news-room/detail/08-04-2020-joint-leader-s-statement---violence-againstchildren-a-hidden-crisis-of-the-covid-19-pandemic. Accessed 11 Apr 2020.

3. World Health Organization. COVID-19 and violence against women What the health sector/system can do. 2020. https://www.axios.com/chinadomestic-violence-. Accessed 11 Apr 2020.

4. International Rescue Committee. Are We There Yet? Progress and challenges in ensuring life-saving services and reducing risks to violence for women and girls in emergencies. 2015. https://www.rescue.org/sites/default/files/ document/664/ircarewethereyetwebfinalukspell.pdf. Accessed 11 Apr 2020

5. International Rescue Committee. "Everything on her shoulders" Rapid assessment on gender and violence against women and girls in the Ebola outbreak in Beni, DRC. 2019. https://www.hrw.org/news/2018/10/03/drcongo-upsurge-killings-. Accessed 11 Apr 2020.

6. Chandan JS, Chandan JK. Considering gender-based violence in vaccine prioritisation strategies. Lancet. 2021;397(10282):1345. https://doi.org/10.101 6/S0140-6736(21)00532-8.

7. Chandan JS, Thomas T, Bradbury-Jones C, Taylor J, Bandyopadhyay S, Nirantharakumar K. Risk of cardiometabolic disease and all-cause mortality in female durvivors of domestic abuse. J Am Heart Assoc. 2020;9(4):e014580. https://doi.org/10.1161/JAHA.119.014580.

8. Williamson EJ, Walker AJ, Bhaskaran K, Bacon S, Bates C, Morton CE, et al. OpenSAFELY: factors associated with COVID-19 death in 17 million patients. Nature. 2020:1-11. https://doi.org/10.1038/s41586-020-2521-4.

9. Sharp-Jeffs N, Kelly L. Domestic Homicide Review (DHR) case analysis report for standing together; 2016.

10. Sabri B, Hartley M, Saha J, Murray S, Glass N, Campbell JC. Effect of COVID19 pandemic on women's health and safety: a study of immigrant survivors of intimate partner violence. 2020;41:1294-312. https://doi.org/10.1080/073 99332.2020.1833012

11. Cegedim Health Data. THIN : The Health Improvement Network - Cegedim Health Data. 2021. https://www.cegedim-health-data.com/cegedim-healthdata/thin-the-health-improvement-network/. Accessed 29 Jul 2021. 
12. Cegedim. Vision medical software | Smarter, faster and better healthcare. 2019. https://www.visionhealth.co.uk/vision-medical-software/. Accessed 30 Dec 2019.

13. Kontopantelis E, Stevens RJ, Helms PJ, Edwards D, Doran T, Ashcroft DM. Spatial distribution of clinical computer systems in primary care in England in 2016 and implications for primary care electronic medical record databases: a cross-sectional population study. BMJ Open. 2018;8(2):20738. https://doi.org/10.1136/bmjopen-2017-020738.

14. Blak BT, Thompson M, Dattani H, Bourke A. Generalisability of The Health Improvement Network (THIN) database: demographics, chronic disease prevalence and mortality rates. Inform Prim Care. 2011;19(4):251-5. http:// www.ncbi.nlm.nih.gov/pubmed/22828580. . https://doi.org/10.14236/jhi.v1 9i4.820.

15. Booth N. What are the Read Codes? Health Libr Rev. 1994;11(3):177-82. https://doi.org/10.1046/J.1365-2532.1994.1130177.X.

16. Chandan JS, Thomas T, Bradbury-Jones C, Russell R, Bandyopadhyay S, Nirantharakumar $\mathrm{K}$, et al. Female survivors of intimate partner violence and risk of depression, anxiety and serious mental illness. Br J Psychiatry. 2019:16. https://doi.org/10.1192/bjp.2019.124.

17. Chandan JS, Thomas T, Raza K, Bradbury-Jones C, Taylor J, Bandyopadhyay $S$, et al. Intimate partner violence and the risk of developing fibromyalgia and chronic fatigue syndrome. J Interpers Violence. 2019:088626051988851. https://doi.org/10.1177/0886260519888515.

18. Chandan JS, Thomas T, Bradbury-Jones C, Taylor J, Bandyopadhyay S, Nirantharakumar K. Intimate partner violence and temporomandibular joint disorder. J Dent. 2019;82:98-100. https://doi.org/10.1016/j.jdent.2019.01.008.

19. Chandan JS, Keerthy D, Gokhale KM, Bradbury-Jones C, Raza K, Bandyopadhyay $\mathrm{S}$, et al. The association between exposure to domestic abuse in women and the development of syndromes indicating central nervous system sensitisation: a retrospective cohort study using UK primary care records. Eur J Pain. 2021:ejp.1750. https://doi.org/10.1002/ejp.1750.

20. Maguire A, Blak BT, Thompson M. The importance of defining periods of complete mortality reporting for research using automated data from primary care. Pharmacoepidemiol Drug Saf. 2009;18(1):76-83. https://doi. org/10.1002/pds.1688.

21. Chandan JS, Thomas T, Gokhale KM, Bandyopadhyay S, Taylor J, Nirantharakumar K. The burden of mental ill health associated with childhood maltreatment in the UK, using The Health Improvement Network database: a population-based retrospective cohort study. Lancet Psychiatry. 2019;6(11):926-34. https://doi.org/10.1016/S2215-0366(19)30369-4.

22. Chandan JS. Improving global surveillance of gender-based violence. Lancet. 2020;396(10262):1562. https://doi.org/10.1016/S0140-6736(20)32319-9.

23. Macdonald M. The role of healthcare services in addressing domestic abuse. 2021. www.parliament.uk/commons-library\%7Cintranet.parliament.uk/ commons-library\%7Cpapers@parliament.uk\%7C@commonslibrary. Accessed 30 Jul 2021.

24. GAVI. Effective ways to increase vaccination rates. 2020

25. Chandan JS, Gokhale KM, Bradbury-Jones C, Nirantharakumar K, Bandyopadhyay S, Taylor J. Exploration of trends in the incidence and prevalence of childhood maltreatment and domestic abuse recording in UK primary care: a retrospective cohort study using "the health improvement network" database. BMJ Open. 2020;10(6):e036949. https://doi.org/10.1136/ bmjopen-2020-036949.

26. Syed S, Ashwick R, Schlosser M, Gonzalez-Izquierdo A, Li L, Gilbert R. Predictive value of indicators for identifying child maltreatment and intimate partner violence in coded electronic health records: a systematic review and meta-analysis. Arch Dis Child. 2021;106(1):44-53. https://doi. org/10.1136/ARCHDISCHILD-2020-319027.

27. Dheensa S. Recording and sharing information about domestic violence/ abuse in the health service; 2020.

\section{Publisher's Note}

Springer Nature remains neutral with regard to jurisdictional claims in published maps and institutional affiliations.

Ready to submit your research? Choose BMC and benefit from:

- fast, convenient online submission

- thorough peer review by experienced researchers in your field

- rapid publication on acceptance

- support for research data, including large and complex data types

- gold Open Access which fosters wider collaboration and increased citations

- maximum visibility for your research: over $100 \mathrm{M}$ website views per year

At BMC, research is always in progress.

Learn more biomedcentral.com/submissions 